\title{
Emergency physician awarded Heart and Stroke Distinguished Service Award
}

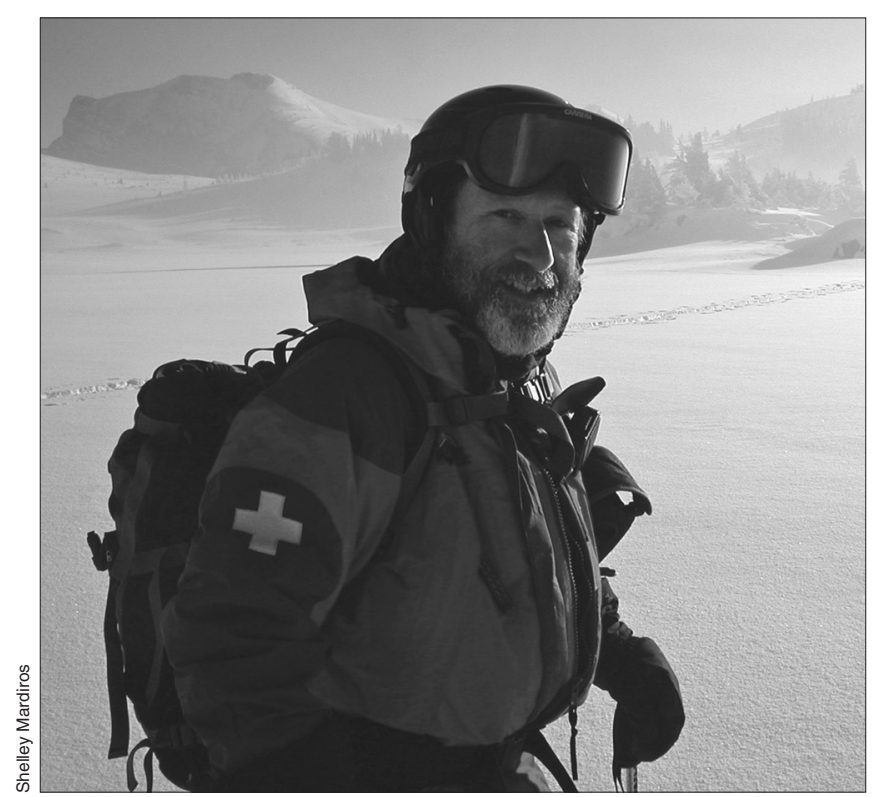

Dr. Michael Shuster

$\mathrm{F}$ or over 15 years, Dr. Michael Shuster has devoted countless hours of volunteer time and leadership energy to the Heart and Stroke Foundation. For his generosity, commitment and service, Dr. Shuster was recently awarded the Heart and Stroke Foundation of Canada Distinguished Service Award.
Participating in committees, subcommittees and coalitions too numerous to list, Shuster began his volunteer committment in 1988 when he attended a Heart and Stroke Foundation conference that discussed the future of emergency cardiac care in Canada. Armed with his own knowledge and a desire to make a difference, Shuster signed on as a volunteer for the Heart and Stroke Foundation of Ontario. Over the years, Dr. Shuster has shaped the future of emergency cardiac care in Canada by developing many Heart and Stroke Foundation policies and position statements at both provincial and federal levels. He has also

\section{Dr. Shuster has shaped the future of emergency cardiac care in Canada ... .}

dedicated many hours to reviewing and improving cardiac care training manuals. In 2003, he accepted a position as the Chair of the Foundation's National Policy Advisory Committee on Resuscitation.

Carolyn Pullen, Assistant Director, Emergency Cardiovascular Care and Health Policy for the Foundation, says "Dr. Shuster has made a permanent and positive mark on the development of resuscitation science and practices in Canada ... [and] his sense of humour never fails us." 